FULL-LENGTH ARTICLE

Manufacturing

\title{
Comparison of umbilical cord tissue-derived mesenchymal stromal cells isolated from cryopreserved material and extracted by explantation and digestion methods utilizing a split manufacturing model
}

\author{
Matthew L. Skiles*, Allen J. Marzan, Katherine S. Brown, Jaime M. Shamonki \\ Research and Development, Generate Life Sciences, Los Angeles, California, USA
}

\section{A R T I C L E I N F O}

\section{Article History:}

Received 9 March 2020

Accepted 9 June 2020

Key Words:

cryopreservation

enzymatic digestion

explant

MSCs

umbilical cord tissue

\begin{abstract}
A B S T R A C T
Background aims: Umbilical cord (UC) tissue is recognized as an advantageous source of mesenchymal stromal cells (MSCs), whose therapeutic properties are being actively evaluated in pre-clinical and clinical trials. In recognition of its potential value, storage of UC tissue or cells from UC tissue in newborn stem cell banks is now commonplace; however, strategies for isolating UC-derived MSCs (UCMSCs) from UC tissue have not been standardized. The majority of newborn stem cell banks take one of two approaches to cord tissue processing and cryopreservation: enzymatic digestion of the fresh tissue with cryopreservation of the subsequent cell suspension or cryopreservation of the tissue as a composite whole with later, post-thaw isolation of cells by explantation. Evaluation of UCMSCs derived by these two principal preparation and cryopreservation strategies is important to understanding whether the methods currently employed by newborn stem cell banks retain the desirable clinical attributes of UC cells.

Methods: UCMSCs were isolated from 10 UC tissue samples by both explantation and enzymatic digestion methods to allow for comparison of cells from the same donor. Cell isolates from both methods were compared pre- and post-cryopreservation as well as after serial passaging. Cell viability, morphology, growth kinetics, immunophenotype, cytokine secretion and differentiation capacity were evaluated.

Results: UCMSCs could be derived from fresh UC tissue by both explantation and digestion methods and from thawed UC tissue by explantation. Initial cell populations isolated by digestion were heterogeneous and took longer to enrich for UCMSCs in culture than populations obtained by explantation. However, once isolated and enriched, UCMSCs obtained by either method showed no significant difference in viability, morphology, rate of proliferation, surface marker expression, levels of cytokine secretion or differentiation capacity.

Conclusions: Derivation of UCMSCs by explantation after thawing UC cryopreserved as a composite tissue may be favorable in terms of initial purity and number of cells achievable by a specific passage. However, we observed no evidence of functional difference between UCMSCs derived by explanation or digestion, suggesting that cells isolated from cryopreserved material obtained by either method maintain their therapeutic properties.
\end{abstract}

(C) 2020 International Society for Cell \& Gene Therapy. Published by Elsevier Inc. This is an open access article under the CC BY-NC-ND license. (http://creativecommons.org/licenses/by-nc-nd/4.0/)

\section{Introduction}

Formally defined in 2006 [1], mesenchymal stromal cells (MSCs) have been widely recognized and explored as promising cell therapy candidates. Favorable characteristics of MSCs include the ability to home to sites of injury [2], as well as self-renewal and rapid

\footnotetext{
* Correspondence: Matthew L. Skiles, PhD, 6550 S Bay Colony Dr, Ste 160, Tucson, Arizona 85756, USA

E-mail address: mskiles@cordblood.com (M.L. Skiles).
}

proliferation [3], and the capacity to differentiate into a variety of cell types [4]. However, the primary therapeutic activity of MSCs appears to be paracrine, with secretion of bioactive factors stimulating local survival and recovery of injured cells [5] as well as modulating local inflammation and immune responses [6]. Pre-clinical and clinical research efforts have therefore focused on indications that might be responsive to regenerative MSC bystander effects, including bone defects, such as in cleft palate [7]; tissue ischemia, such as in myocardial infarction [8] or stroke [9]; disorders associated with neuro-inflammation, such as traumatic brain injury [10], 
cerebral palsy [11] and neonatal stroke [12]; disorders with associated chronic inflammation, such as bronchopulmonary dysplasia [13]; conditions of autoimmune dysregulation, such as lupus erythematosus [14]; and conditions of undesirable immune response, such as graft-versus-host disease [15].

MSCs can be isolated from a variety of adult tissues, such as bone marrow, adipose tissue and dental pulp, as well as perinatal tissues, including the amnion, placenta and umbilical cord (UC) [16]. Perinatal sources of MSCs are attractive because of the relatively easy and non-invasive manner in which tissues can be collected following birth, reduced risk of exposure to viral and environmental toxins, enhanced proliferative profile and the relative immaturity that MSCs from perinatal tissues demonstrate compared with those from other sources [17]. The Wharton jelly of UC tissue, in particular, is highly enriched in MSCs [18]. Unlike the placenta, UC tissue is also entirely of fetal origin, thereby avoiding any ambiguity in the donor source of derived cells. It is possible that it is for these reasons Couto et al. report that UC-derived MSCs (UCMSCs) "are both the dominant perinatal cell type in clinical trials, and since 2016 umbilical cord tissue is the dominant source of MSC for all MSC clinical trials" [19].

Growing recognition of the therapeutic potential of UCMSCs and the progress toward their clinical application have resulted in the rapid emergence and growth of UC tissue banking services [20]. However, while there is wide consensus on the value of collecting and preserving perinatal UC tissue, which would otherwise be discarded as medical waste, there has been less agreement on or standardization of tissue-processing methodologies. Isolation of UCMSCs from UC tissue is primarily achieved by one of two approaches: explantation or enzymatic digestion. In the explantation approach, small pieces of the composite tissue are cultured on plasticware in media designed to be supportive of MSCs. This method allows for the natural migration of MSCs out of the UC tissue and simultaneously extracts and enriches the cells. However, the typical time to MSC harvest is 10-14 days. Banks that elect to derive MSCs from cord tissue by the explantation method generally cryopreserve the composite tissue and isolate the cells following thaw. Alternatively, in the enzymatic digestion approach, proteolytic enzymes such as collagenase and hyaluronidase are applied to the cord tissue to break down the tissue's matrix, thus liberating the cells. This method allows for rapid acquisition of cord tissue cells; however, the liberated cells represent a mixed population, and additional steps must be taken to enrich for MSCs. Furthermore, there is risk of the enzymatic cocktail damaging the cells during the digestion process if care is not taken. Banks electing to derive MSCs from cord tissue by enzymatic digestion generally extract the cellular component from the fresh tissue and then cryopreserve the cellular isolate.

As the prevalence of UC tissue banking continues to grow, there is value in evaluating the characteristics of UCMSCs isolated by these two predominant, yet very different, cryopreservation and isolation methods to determine the suitability of cells derived by either approach for potential clinical utilization. In this study, we compare the explantation and digestion methods of MSC isolation in the same UC tissue samples in terms of identity and functionality of MSCs isolated by each method, with a focus on the post-thaw properties of the cells to determine if the cryopreservation and isolation method impacts cellular attributes anticipated to be useful in clinical settings.

\section{Methods}

\section{UC tissue collection and pre-processing}

Ten donated umbilical cords were collected from consenting mothers following delivery ( $>37$ weeks' gestation) and transported to a processing facility in a buffered saline solution containing gentamicin sulfate. Cords were rinsed, decontaminated in alcohol and divided into two segments. For each cord, one segment was designated for processing as composite tissue pieces, and one segment was designated for enzymatic digestion.

\section{Processing and cryopreservation of composite UC tissue}

Cord segments for composite tissue processing were placed into a sterile Petri dish and cut into $1-\mathrm{cm}$ "ringlet" segments using a sterile scalpel. Ringlets were bisected into half ringlets, placed into a $50-\mathrm{mL}$ tube with sterile Dulbecco's phosphate-buffered saline (DPBS) (Mediatech, Inc, Manassas, VA, USA) and vortexed to remove blood. Rinsed half ringlets were transferred into a sterile Petri dish, and a sterile 4mm biopsy punch was used to excise 41 small tissue pieces of consistent size for explant outgrowth and metabolic activity assays. The remaining, un-biopsied half ringlets were placed into 5-mL cryotubes containing $2 \mathrm{~mL}$ of cryopreservation medium (CryoStor CS10; BioLife Solutions, Bothell, WA, USA), with each tube receiving approximately $2-2.5 \mathrm{~g}$ of composite tissue. The vials were placed into a $-80^{\circ} \mathrm{C}$ freezer, inside a passive controlled-rate freeze device (CoolCell; BioCision LLC, Larkspur, CA, USA), then transferred into cryogenic storage in $\mathrm{LN}_{2}$ vapor after $18-24 \mathrm{~h}$. After at least 1 week in cryopreservation, tissue was thawed and explanted in MSC-supporting medium (MesenCult-XF; Stemcell Technologies, Vancouver, Canada) for isolation and enrichment of composite tissue UCMSCs (c-UCMSCs). C-UCMSCs were expanded to the end of passage three, then harvested and evaluated for apparent immunophenotype, growth kinetics, secretory profile and differentiation capacity.

\section{Isolation of cells from UC tissue by explant outgrowth}

Isolation of MSC-like cells from UC tissue was performed as previously described [21]. Briefly, 25 excised pieces of composite UC tissue were plated in a $5 \times 5$ grid pattern onto a 10 - $\mathrm{cm}$ plastic culture dish pre-treated with an attachment-promoting substrate (MesenCult-SF attachment substrate; Stemcell Technologies). The total weight of tissue in the plate was recorded, and the pieces were allowed to sit dry for 10 minutes to ensure adherence and maintenance of position. Ten milliliters of expansion medium (MesenCult-XF; Stemcell Technologies) was added, and the cultures were placed into incubation. After 7 days, the tissue and medium were discarded and $10-\mathrm{mL}$ fresh medium was added. After another 7 days, the cells were harvested, counted and subcultured.

\section{Enzymatic digestion of UC tissue and cryopreservation of isolated cells}

Cord segments for digestion were weighed and then placed into a sterile Petri dish, cut longitudinally with a scalpel and spread open to expose the Wharton jelly. Multiple lateral cuts were made to score blood vessels, and blood and clots were scraped and rinsed away with DPBS. The entire tissue was then finely minced into 2- to 4-mm pieces. Minced tissue was transferred to a sterile collection cup to which $0.5 \mathrm{~mL}$ Hylenex (150 USP U/mL; Halozyme Therapeutics, San Diego, CA, USA) and $1 \mathrm{~mL}$ Liberase $(5 \mathrm{mg} / \mathrm{mL}$; Roche Diagnostics $\mathrm{GmbH}$, Mannheim, Germany) were added. The cup was capped and placed onto a rotating platform within a $37^{\circ} \mathrm{C}$ incubator for $1.5-2 \mathrm{~h}$. Enzymes were neutralized with $60 \mathrm{~mL}$ DPBS, and the entire preparation was transferred into a $400-\mu \mathrm{m}$ mesh size strainer bag (Stomacher Lab Systems, Seward, Worthington, West Sussex, UK). The digest was agitated and kneaded, and the filtrate was then passed through a cell strainer $(100-\mu \mathrm{m}$ mesh size; Fisher Scientific, Waltham, MA, USA) and collected in a 50-mL conical tube. The resulting cellular suspension was centrifuged at 400 rcf for 10 minutes, the supernatant was removed and the cell pellet was resuspended in fresh DPBS. The rinsed suspension was centrifuged a second time and 
resuspended in $26 \mathrm{~mL}$ of fresh medium (MesenCult-XF; Stemcell Technologies). Two milliliters of cellular suspension was removed for total cell count determination, immunophenotyping and initiation of fresh primary culture. The remaining $24 \mathrm{~mL}$ was centrifuged at 400 rcf for 10 minutes, followed by removal of the supernatant and resuspension of the cell pellet in $24 \mathrm{~mL}$ of cold cryopreservation medium. The suspension was aliquoted into 5 - $\mathrm{mL}$ cryovials and placed into a $-80^{\circ} \mathrm{C}$ freezer inside a passive controlled-rate freeze device. At between 18 and $24 \mathrm{~h}$, the vials were transferred into cryogenic storage in $\mathrm{LN}_{2}$ vapor. After at least 1 week in cryopreservation, cells were thawed and cultured in MSC-supporting medium (MesenCult-XF; Stemcell Technologies) for enrichment of MSC-like cells from digested tissue UCMSCs (d-UCMSCs). D-UCMSCs were expanded to the end of passage three, then harvested and evaluated for apparent immunophenotype, growth kinetics, secretory profile and differentiation capacity.

\section{AlamarBlue assay of composite UC tissue metabolic activity}

Quantitative assessment of the metabolic status of composite UC tissue was performed as previously described [21]. Briefly, 16 excised pieces of composite UC tissue were placed four to a well into four wells of an untreated 24-well plate. Four hundred fifty microliters of medium and $50 \mu \mathrm{L}$ of AlamarBlue metabolic indicator dye (Thermo Fisher Scientific, Waltham, MA, USA) were added to each well. One well containing medium only and one well containing medium and AlamarBlue but no tissue were also prepared as a blank and control, respectively. Well plates were incubated for 23 hours, then medium from each well was sampled and the absorbance at $570 \mathrm{~nm}$ and $600 \mathrm{~nm}$ was measured. Percent dye reacted was calculated from the measured values.

\section{Cell enumeration}

Enumeration of cells from freshly digested UC tissue and of thawed cells from digested tissue was performed by hemocytometer. Enumeration of cells collected at the end of explant culture, of expanded c-UCMSCs and d-UCMSCs at the end of each passage and of daily samples during growth curve analysis studies was performed using a handheld cytometer (Scepter 2.0 handheld automated cell counter; Millipore Corporation, Billerica, MA, USA).

\section{Cell viability}

Viability of thawed cells from digested tissue and of cells harvested at the end of explant culture of thawed composite UC tissue was performed by Trypan Blue (Sigma-Aldrich, St Louis, MO, USA) dye exclusion. Viability of passage three c-UCMSCs and d-UCMSCs expanded from thawed material was performed by both Trypan Blue dye exclusion and 7-aminoactinomycin D (Becton, Dickinson and Company, Franklin Lakes, NJ, USA) staining and analysis by flow cytometer.

\section{Immunophenotyping}

Cells from freshly digested UC tissue and from passage three c-UCMSCs and d-UCMSCs expanded from thawed material were washed, blocked and incubated with fluorochrome-conjugated antihuman antibodies to CD73 (mouse; Becton, Dickinson and Company), CD90 (mouse; Beckman Coulter, Inc, Brea, CA, USA), CD34 (mouse; Beckman Coulter) and CD45 (mouse; Beckman Coulter). Stained cells were then washed and analyzed on a FC500 flow cytometer (Beckman Coulter).

\section{Growth curve analysis}

Passage three c-UCMSCs and d-UCMSCs expanded from thawed material were harvested and counted, then seeded at 60,000 cells per well into five wells of a six-well plate pre-treated with attachmentpromoting substrate (MesenCult-SF attachment substrate; Stemcell Technologies). The medium volume per well was brought up to $2 \mathrm{~mL}$ and the plates were placed into incubation. After $24 \mathrm{~h}$ (day 1), $48 \mathrm{~h}$ (day 2), $72 \mathrm{~h}$ (day 3), $96 \mathrm{~h}$ (day 4) and $168 \mathrm{~h}$ (day 7), cells from a single well were trypsinized, harvested and counted.

\section{Cytokine secretion analysis}

Passage three c-UCMSCs and d-UCMSCs expanded from thawed material were harvested and counted, then seeded at 100,000 cells per well in $0.5 \mathrm{~mL}$ medium (MesenCult-XF; Stemcell Technologies) into four wells of a 24-well plate pre-treated with attachment-promoting substrate (MesenCult-SF attachment substrate; Stemcell Technologies). Cells were incubated overnight to allow for attachment, then the medium was removed, the cells were rinsed with DPBS and $0.5 \mathrm{~mL}$ of fresh medium was added to each well. A well with medium but without cells was also prepared as a control. Plates were returned to incubation for $48 \mathrm{~h}$, then medium was sampled and analyzed by enzyme-linked immunosorbent assay (ELISA) for soluble secreted growth factors. ELISA kits for IL-6, fibroblast growth factor 2, macrophage colony-stimulating factor (M-CSF) and transforming growth factor $\beta 1$ were purchased from Invitrogen (Carlsbad, CA, USA), and ELISA kits for vascular endothelial growth factor (VEGF) were purchased from Novus Biologicals (Centennial, CO, USA). All assays were performed in accordance with kit manufacturers' instructions.

\section{Differentiation analysis}

Thawed passage three c-UCMSCs and d-UCMSCs were seeded into T150 flasks (Corning Incorporated, Corning, NY, USA) and expanded to the end of P4. Cells were harvested and counted, and then seeded for differentiation. For osteogenic differentiation, cells were seeded at 20,000 cells per well in $0.5 \mathrm{~mL}$ medium (MesenCultXF; Stemcell Technologies) in a 48-well, fibronectin-coated plate (Biocoat; Corning Incorporated, Corning, NY, USA). For adipogenic differentiation, cells were seeded at 60,000 cells per well in $1 \mathrm{~mL}$ medium in a 24-well plate. For chondrogenic differentiation, 250,000 cells per tube were pelleted in $5 \mathrm{~mL}$ medium in $15-\mathrm{mL}$ centrifuge tubes at $300 \mathrm{rcf}$ for 5 minutes. After overnight incubation, medium was aspirated and replaced with osteogenic (MesenCult osteogenic differentiation medium; Stemcell Technologies), adipogenic (AdipoMAX; MilliporeSigma, Burlington, MA, USA) and chondrogenic (ChondroMAX; MilliporeSigma) induction media, respectively. The cells were placed into an incubator for 4 weeks, with media exchanges every three days. Control samples with growth medium (MesenCult-ACF Plus; Stemcell Technologies) in place of differentiation induction media were also prepared for each condition.

Osteogenic differentiation was detected by fixation of monolayer cells in 4\% paraformaldehyde (Thermo Scientific, Waltham, MA, USA) and staining with Alizarin Red S (Electron Microscopy Sciences, Hatfield, PA, USA). Additionally, osteogenically induced cells from an identical setup were harvested and assessed colorimetrically for alkaline phosphatase activity (MBL International Corporation, Woburn, MA, USA) following the kit manufacturer's instructions. Adipogenic differentiation was detected by fixation of monolayer cells in $4 \%$ paraformaldehyde and staining with Oil Red O (Sigma Life Science, St Louis, MO, USA). Chondrogenic differentiation was detected by fixation of micromass cultures in $4 \%$ paraformaldehyde, paraffin 
embedding and sectioning of the cultures and staining with Alcian Blue (Electron Microscopy Sciences).

\section{Data analysis}

Results are displayed as average \pm standard deviation. Significance of differences between sample group means was determined by paired $t$-test, with $P<0.05$ indicating significance.

\section{Results}

\section{Quality assessment of UC tissue}

Quality of umbilical cords was assessed by metabolic activity assay of the fresh and thawed composite tissues, as previously described [21]. AlamarBlue metabolic indicator dye was $63.1 \% \pm 7.2 \%$ and $57.7 \% \pm 15.1 \%$ reacted in the presence of fresh and thawed UC tissue, respectively (Figure 1), and these values were in line with values we commonly measure for UC tissue.

\section{Cell yields from explanted and digested UC tissue}

Of the 10 fresh UC samples prepared, one exhibited contamination, resulting in data from the sample being discarded for post-thaw comparisons of either method. Explantation and digestion methods differed significantly in the amount of tissue processed for cell isolation (Figure 2A). On average, approximately $0.6 \mathrm{~g}$ of tissue was required to prepare one explant plate, whereas an average of $15.0 \mathrm{~g}$ of tissue was digested enzymatically. Average total cell yields from explanted and digested fresh tissues were $3.36 \times 10^{6} \pm 0.58 \times 10^{6}$ cells and $4.04 \times 10^{7} \pm 3.02 \times 10^{7}$ cells, respectively (Figure 2B). However, because of the difference in material volume processed, the per gram cell yield was significantly higher for explanted tissue compared with digested tissue $\left(6.12 \times 10^{6} \pm 1.81 \times 10^{6}\right.$ cells/g vs $2.68 \times 10^{6} \pm$ $2.05 \times 10^{6} \mathrm{cells} / \mathrm{g}$ ) (Figure 2D). Additionally, post-thaw cell yield from explants $\left(4.67 \times 10^{6} \pm 4.53 \times 10^{6}\right.$ cells $\left./ g\right)$ did not significantly differ from fresh tissue, while digested material saw a significant reduction in total cell recovery following thaw $\left(0.79 \times 10^{6} \pm 0.51 \times 10^{6} \mathrm{cells} / \mathrm{g}\right)$.

C-UCMSCs were harvested from explant cultures on day 14 , consistently yielding on the order of $10^{6}$ cells/g at the end of $\mathrm{P} 0$ at that

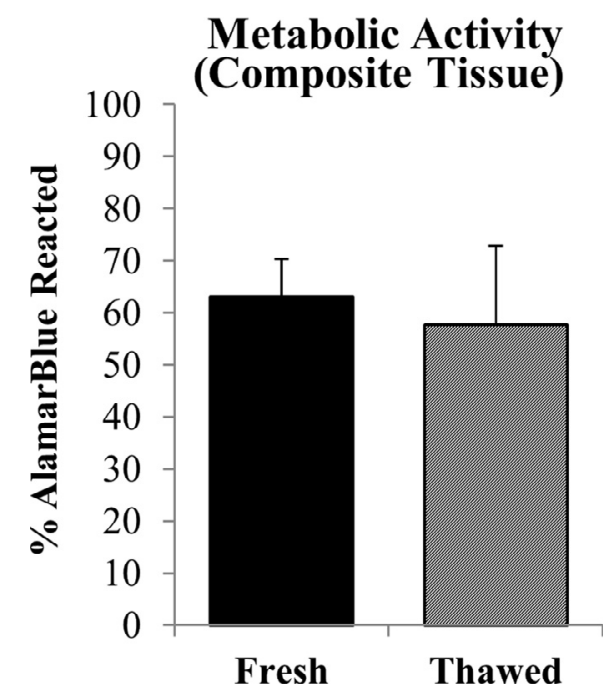

Fig. 1. Quality assessment measures of fresh and cryopreserved then thawed composite UC tissue. There was no significant difference in the percentage of AlamarBlue metabolic indicator dye reacted in the presence of composite UC tissue for 23 hours when calculated for fresh and thawed UC tissue from measurements of absorbance at $570 \mathrm{~nm}$ and $600 \mathrm{~nm}$. time point (Figure 2C). Alternatively, cell isolates from digested tissue were cultured until at least one confluent colony was observed. The average time to cell harvest for d-UCMSCs was 16 days, while $40 \%$ of samples required $>20$ days before cells could be collected. The average d-UCMSC cell yield at the end of P0 was $0.14 \times 10^{6} \pm 0.11 \times 10^{6}$ cells/g, which was significantly lower than the P0 c-UCMSC count $\left(4.67 \times 10^{6} \pm 4.53 \times 10^{6}\right.$ cells/g, $\left.P=0.02\right)$ (Figure $2 \mathrm{D}$ ) as well as the total cell count for digested tissue immediately following thaw $\left(0.79 \times 10^{6} \pm 0.51 \times 10^{6}\right.$ cells $\left./ g, P=0.004\right)$. Variation in initial per gram total cell yield for fresh digested tissues, which displayed a coefficient of variation of $76.4 \%$, may account for some of the variance observed in culture results.

\section{Morphology of cells cultured from explanted and digested UC tissue}

Figure 3 indicates the morphologies of cultured cells derived from cord tissue by explantation and digestion. Both c-UCMSCs and d-UCMSCs displayed a common spindle-shaped morphology that was fibroblast-like. Cells were strongly adherent to culture plastic and proliferated rapidly. Individual colonies of c-UCMSCs in explant cultures consistently reached an almost layered confluence by day 14. After passaging, c-UCMSC and d-UCMSC cultures displayed elongated, primarily bipolar, cells that were visually indistinguishable from one another.

\section{Viability of cells derived by explantation and digestion}

Viabilities of cell populations isolated at the end of explant and from digested tissues were $85.8 \% \pm 7.1 \%$ and $69.9 \% \pm 25.5 \%$, respectively (Figure 4 ). These values were significantly lower than viability percentages for corresponding cells that had been passaged $(94.5 \% \pm$ $1.9 \%$ and $95.4 \pm 1.5 \%$, respectively). Percent viability did not differ significantly between processing methods at either point.

\section{Immunophenotype of cells derived by explanation and digestion}

The initial cell isolate from freshly digested tissue showed low expression of MSC markers CD73 (2.37\% $\pm 1.55 \%)$ and CD90 (4.64\% \pm $2.88 \%$ ) and hematopoietic markers CD34/45 (4.39\% $\pm 2.90 \%)$ (Figure 5A). Following thaw, these markers were expressed at somewhat higher, although still low, levels: $4.76 \% \pm 3.43 \%(P=0.056)$, $12.12 \% \pm 7.79 \%(P=0.037)$ and $6.93 \% \pm 5.19 \%(P=0.059)$, respectively, for CD73, CD90 and CD34/45. Following passage, expression of MSC markers was dramatically increased (CD73, 98.42\% $\pm 1.69 \%$; CD90, 95.18\% $\pm 2.39 \%$ ), while expression of CD34/45 (1.43\% $\pm 1.65 \%)$ remained low. Passaged c-UCMSCs also displayed high levels of CD73 and CD90 expression $(99.02 \% \pm 1.59 \%$ and $93.89 \% \pm 5.24 \%$, respectively) and low levels of $\mathrm{CD} 34 / 45$ expression $(0.82 \% \pm 1.50 \%)$, which did not differ significantly from passaged d-UCMSCs (Figure 5B).

\section{Growth kinetics of cells derived by explanation and digestion}

Seven-day growth curves for c-UCMSCs and d-UCMSCs are shown in Figure 6A. Cell count did not significantly differ between methods for any study day. One-week fold increase in cell number was $6.71 \pm$ 2.67 for c-UCMSCs and $8.05 \pm 3.18$ for d-UCMSCs, which was not significantly different $(P=0.24)$. Minimum doubling times were observed between days 3 and 4 and did not differ between c-UCMSCs and d-UCMSCs ( 1.21 days \pm 0.27 days and 1.22 days \pm 0.40 days, respectively, $P=0.94$ ) (Figure $6 \mathrm{~B}$ ).

\section{Cytokine secretion from cells derived by explantation and digestion}

Levels of cytokine secretion from c-UCMSCs and d-UCMSCs are shown in Figure 7A-E. VEGF was most strongly secreted but only under hypoxic induction, with 116- and 211-fold increases in 
A

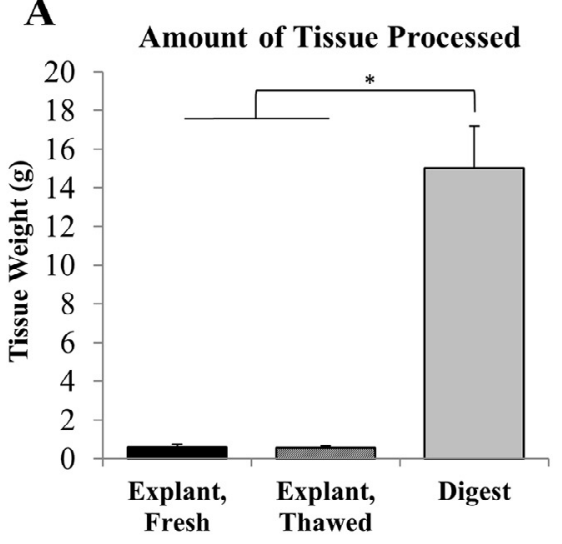

C

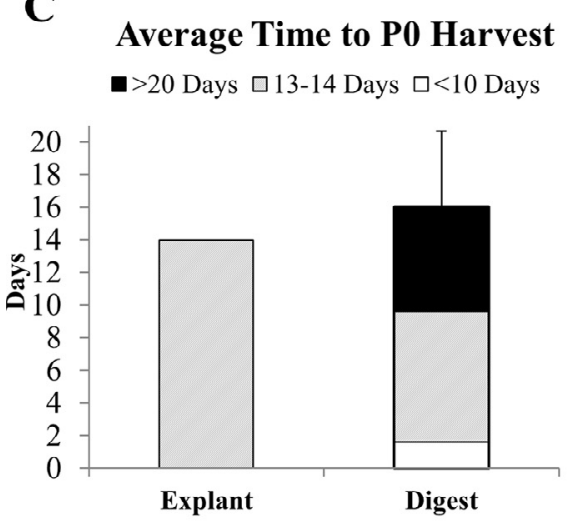

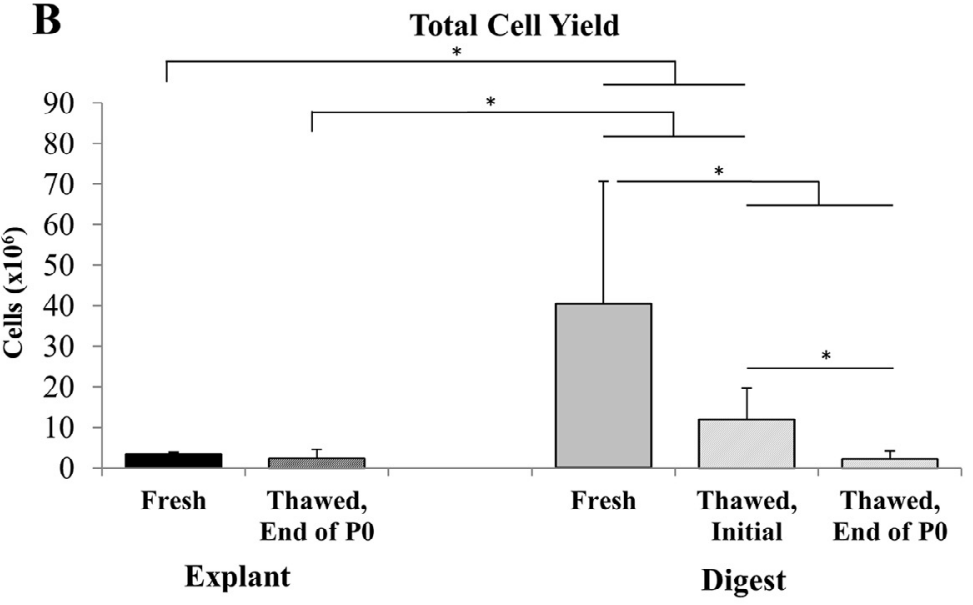

D

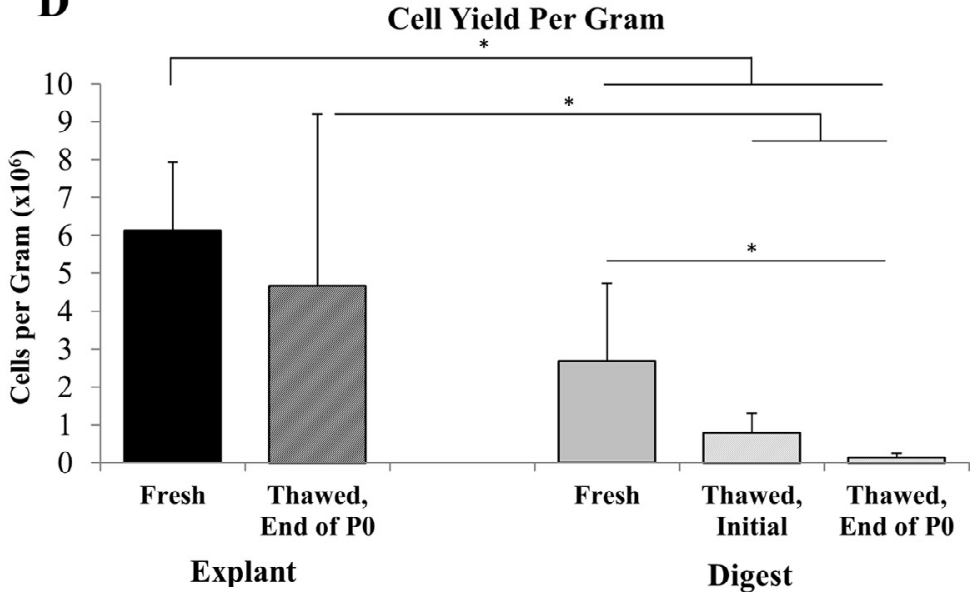

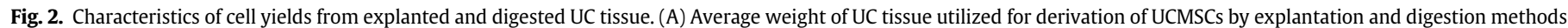

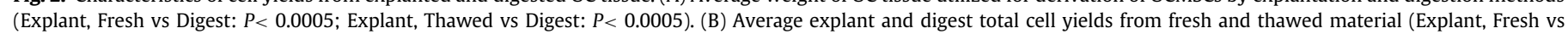

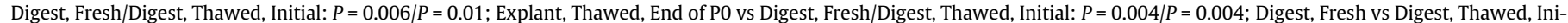

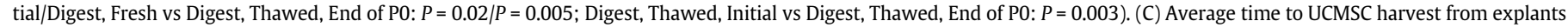

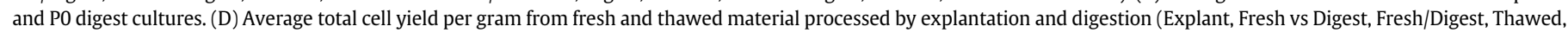

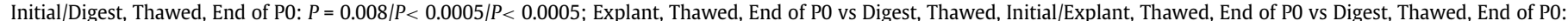

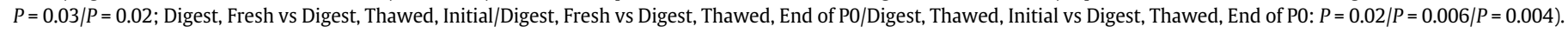

concentration in culture media for c-UCMSCs and d-UCMSCs, respectively, compared with culture at ambient oxygen concentrations (Figure 7F). Differences in levels of secretion between explant and digest were not significant, although there was considerable variation in secretion between donor tissue samples, as shown by levels of secretion from three representative samples in Figure $7 \mathrm{G}-\mathrm{H}$.

\section{Differentiation of c-UCMSCs and d-UCMSCs}

Both c-UCMSCs and d-UCMSCs displayed the capability to differentiate along osteogenic, adipogenic and chondrogenic lineages (Figure 8). Compared with cells cultured in control medium, cells cultured in osteogenic medium displayed clear evidence of calcium deposition. Additionally, c-UCMSCs and d-UCMSCs exhibited $2.66 \pm$ 2.84 -fold and $2.90 \pm 3.41$-fold increases $(P=0.84)$ in alkaline phosphatase activity following osteogenic induction. C-UCMSCs and d-UCMSCs also exhibited lipid accumulation following culture in adipogenic induction medium. To induce chondrogenic differentiation, c-UCMSCs and d-UCMSCs were cultured in micromass pellets. Chondrogenically stimulated pellets displayed better cohesion and cellular condensation compared with control pellets, with stronger mucopolysaccharide staining. Distribution and degree of staining did not appear to differ between c-UCMSCs and d-UCMSCs.

\section{Discussion}

In this article, we evaluate the outcome of the two primary processing methods for the extraction of UCMSCs from UC tissue, explant culturing and enzymatic digestion, in regard to the characteristics of the cellular populations that are initially isolated by each process as well as the final cellular product achieved through enrichment and expansion from previously cryopreserved material. Cultures exhibited uniform fibroblastic morphology and strong plastic adherence. Morphological and flow cytometric analyses indicate that, following expansion, cells derived by either approach are primarily MSC-like. We have previously shown that cells isolated from UC tissue by the explantation method meet the minimal immunophenotypic criteria for identification as MSCs [21]. In this study, an abbreviated panel of positive and negative surface markers such as CD73, CD90, CD34 and CD45 were analyzed and found to be expressed at levels that are consistent with an MSC-like phenotype. Greater than $98 \%$ of cells isolated by either method expressed the MSC marker CD73, and greater than $93 \%$ of cells expressed the MSC marker CD90, while $1 \%$ or fewer cells expressed the hematopoietic markers CD34 and CD45. The cells also proliferated rapidly, with a typical doubling time of 29 hours, which is consistent with previously reported values for UCMSCs ranging from 23 to $48 \mathrm{~h}$ [22]. 


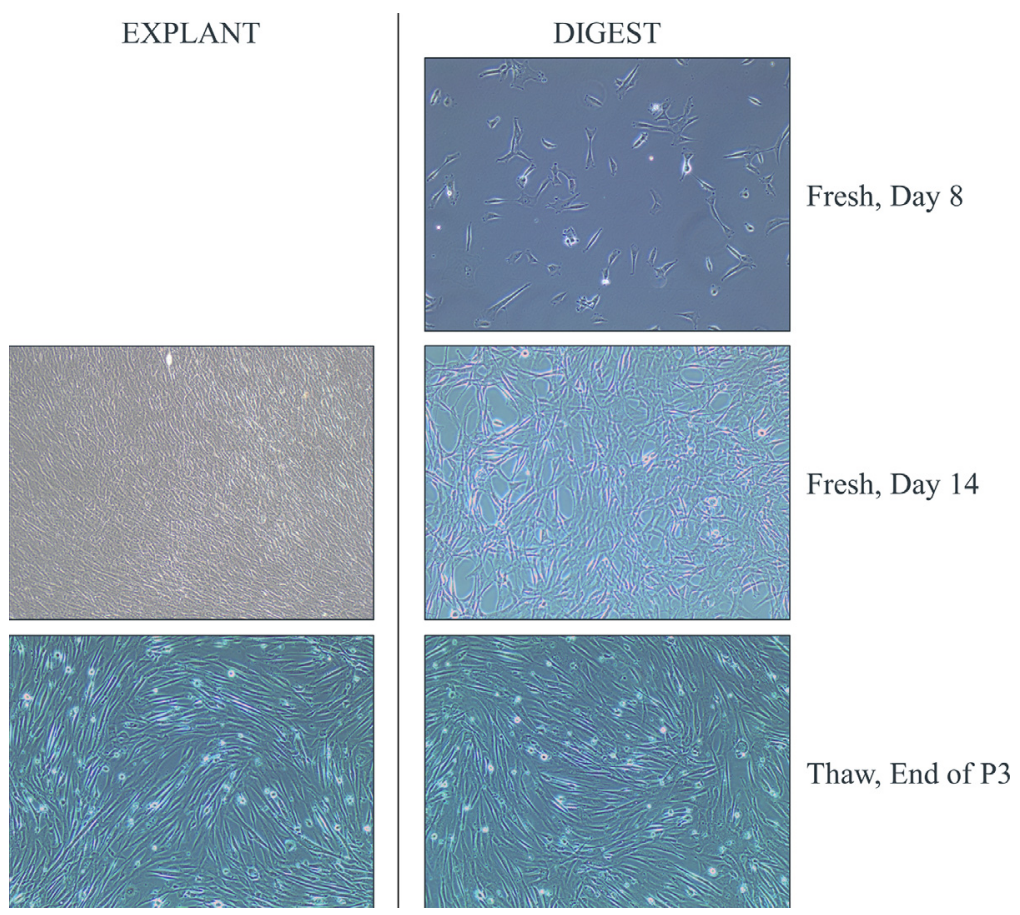

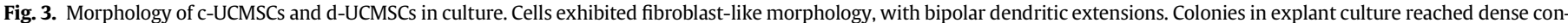

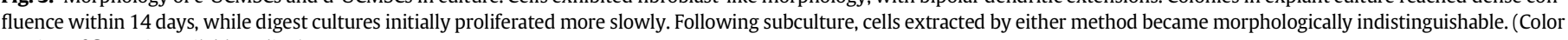
version of figure is available online).

By contrast, the initial cell isolates from explanted and digested UC tissue differed in composition from one another. In addition to MSCs, the umbilical cord contains a number of other cell types, including endothelial cells in the arteries and vein, fibroblasts in the Wharton jelly, epithelial cells in the amnion and a variety of hematopoietic cells in the cord blood [23]. Indeed, published estimates put the number of colony-forming MSCs at between only one in 300 cells [24] and one in 1609 cells [25] found in the UC tissue. Enzymatic digestion of the UC tissue allows for liberation of all the constituent cell populations, producing a cell product that is initially heterogeneous. Flow cytometric analysis indicated that only $2-5 \%$ of total cells collected immediately following UC tissue digestion were positive for expression of CD73 or CD90. Furthermore, following seeding into culture, only a small number of these cells produced proliferative colonies. This indicates that of the cells initially collected from UC tissue by digestion, only a small percentage are in fact desirable, MSClike cells. This supposition is supported by the reddish appearance of the cell pellet following centrifugation of the digest filtrate, which might indicate significant presence of erythrocytes, and the initial slow rate of growth of the cells in primary culture, indicating a low initial seeding density of UCMSCs.

We report a lower and more variable number of MSC-like cells in the initial digest isolates than from explant harvests. Variability in extracted cell yield and heterogeneity of extracted cell product, as were observed in this study, have been noted elsewhere in the literature [26-28]. Furthermore, unpublished digestion procedures

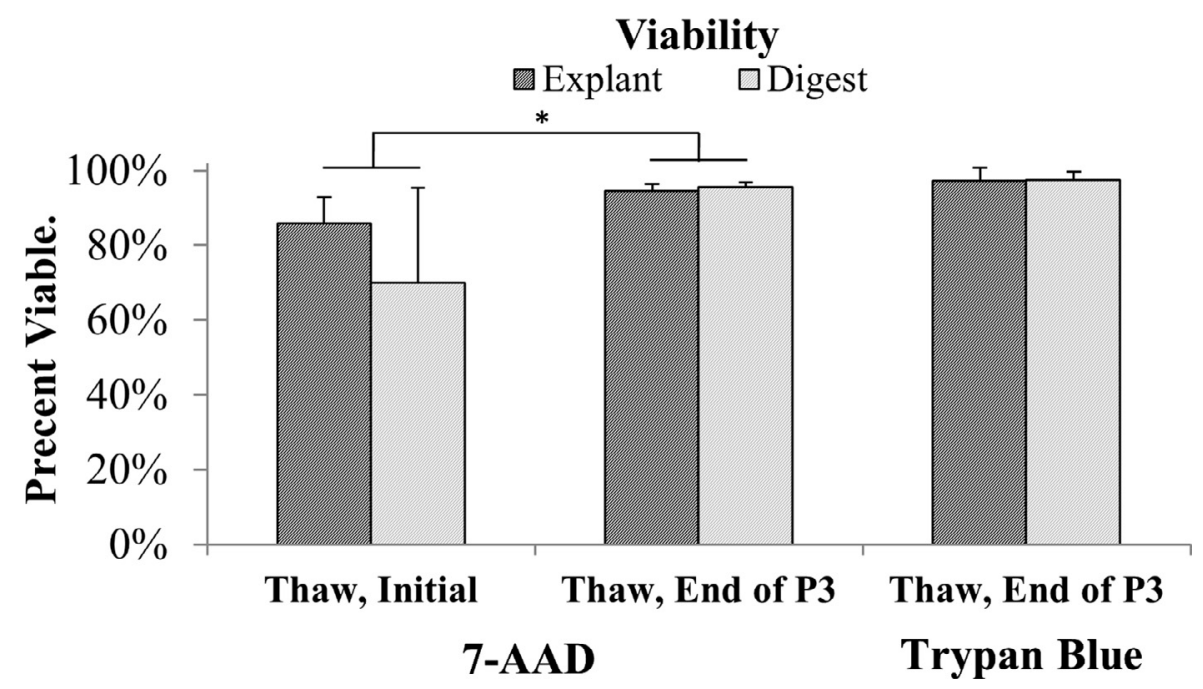

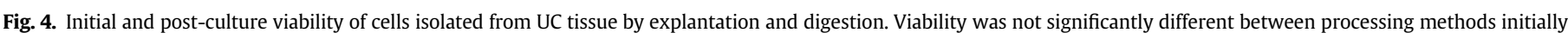

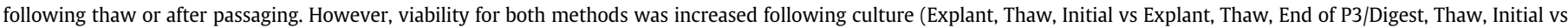

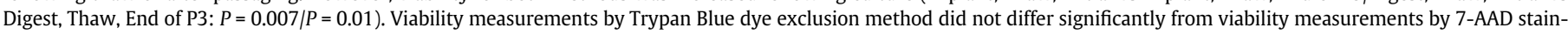
ing. 7-AAD, 7-aminoactinomycin $\mathrm{D}$. 


\section{Digested Tissue}

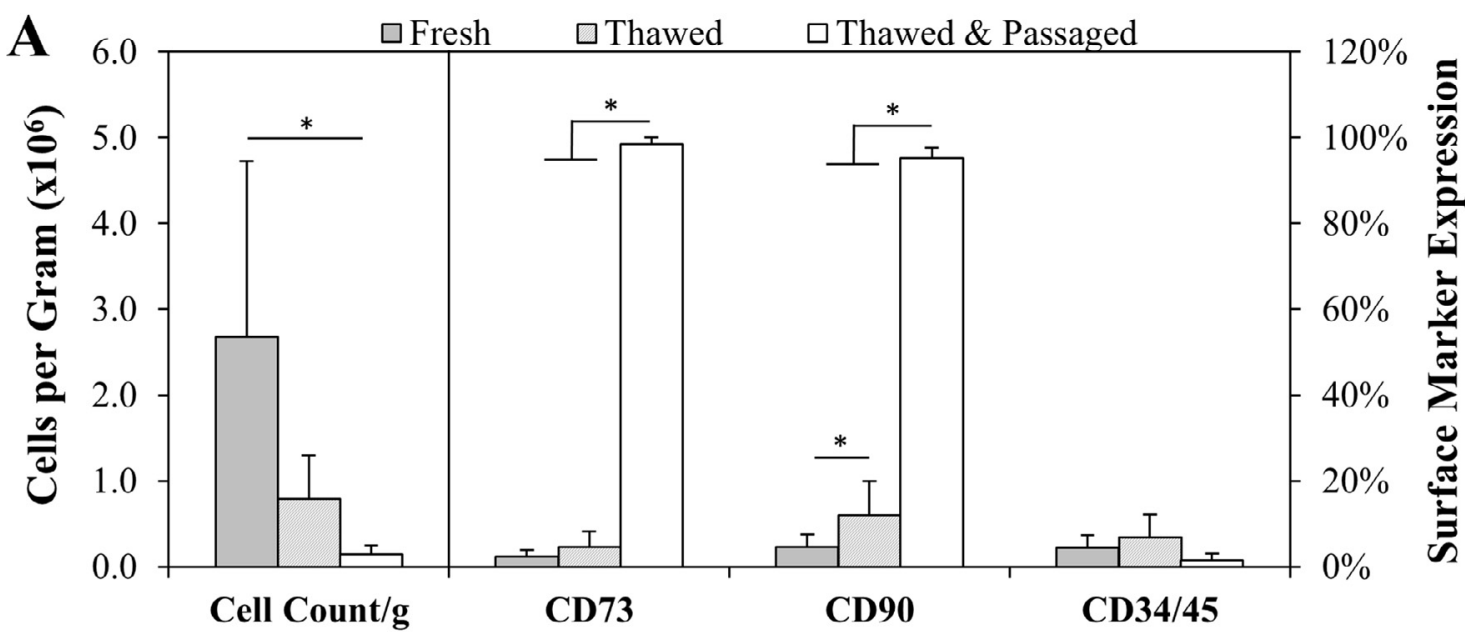

Surface Marker Expression

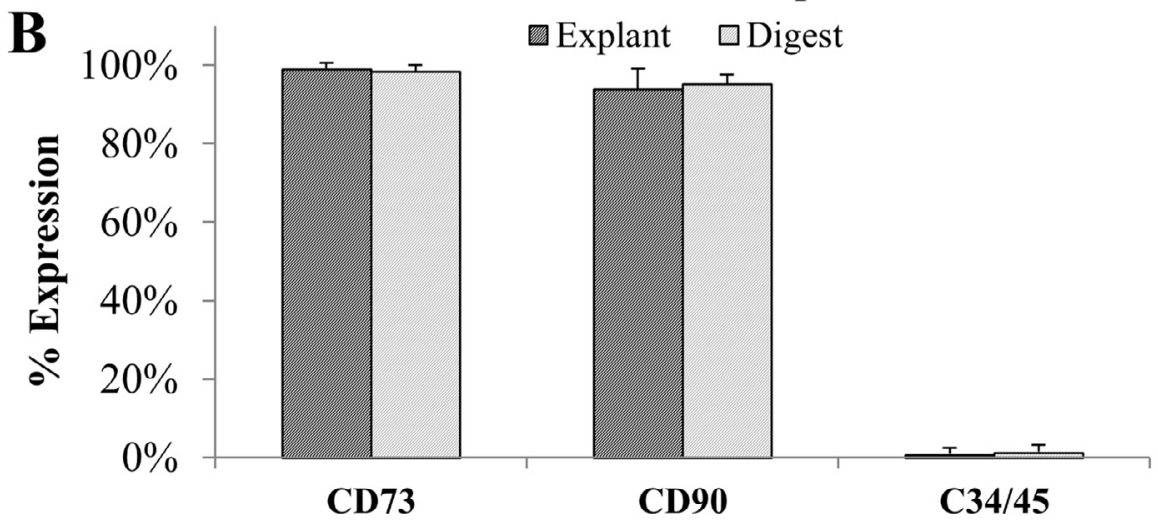

Thawed, End of P3

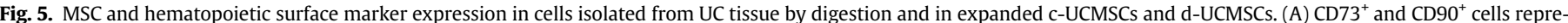

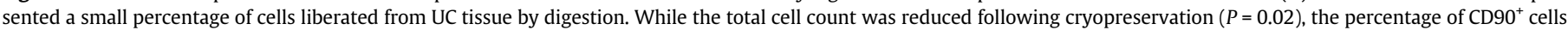

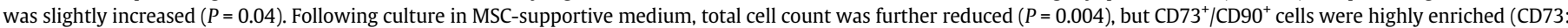

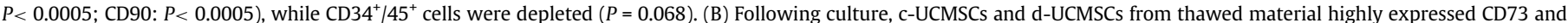
$\mathrm{CD} 90$ and minimally expressed CD34/45, with no significant difference between cells derived by each method.
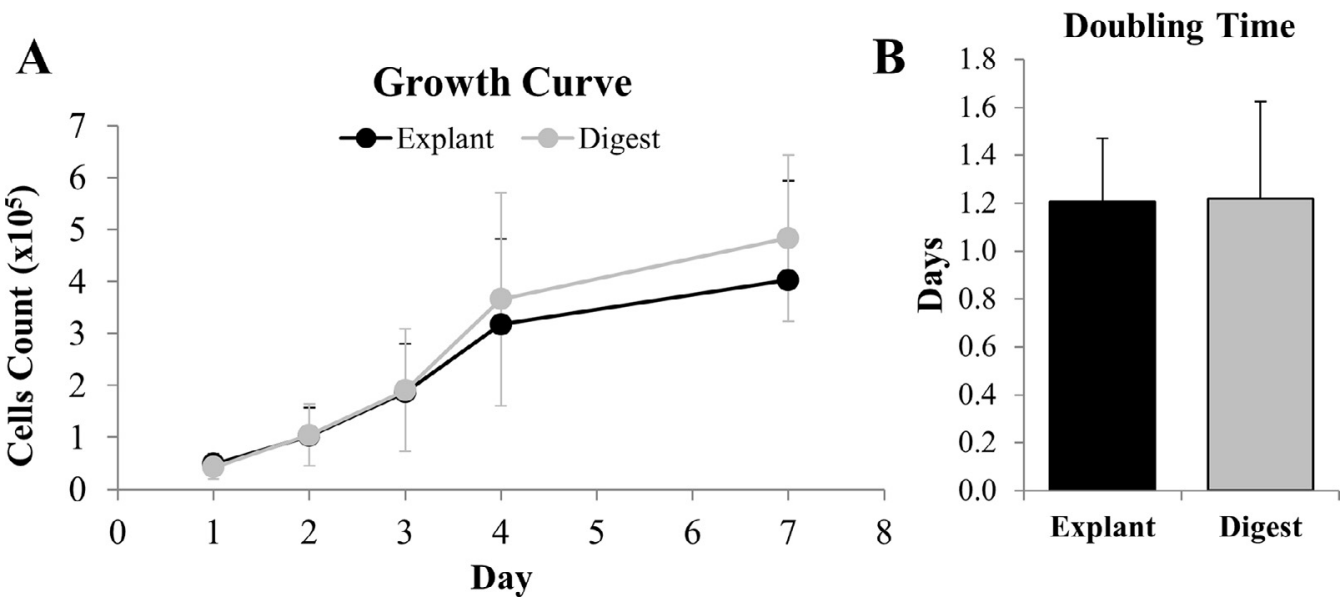

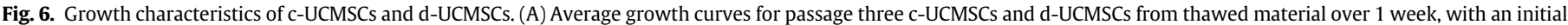

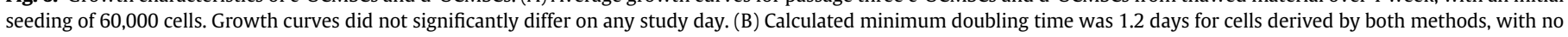
significant difference. 
A

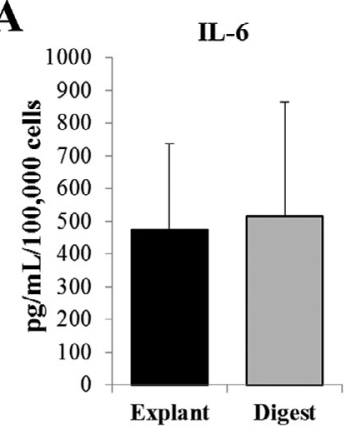

B

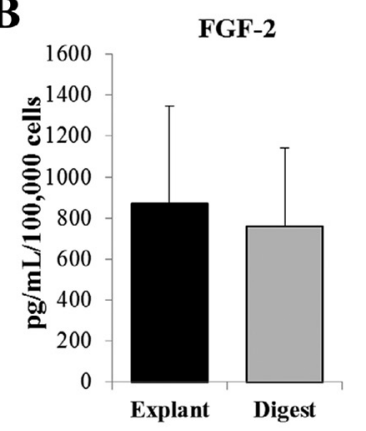

F

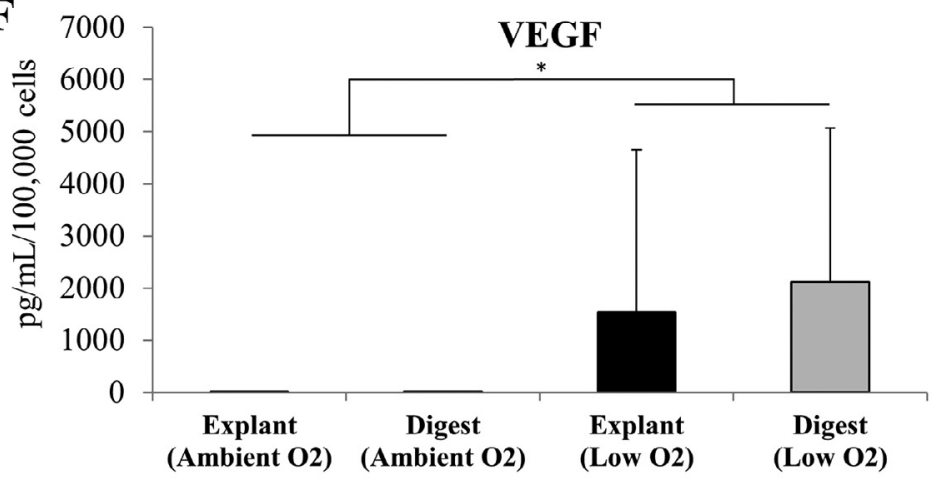

C

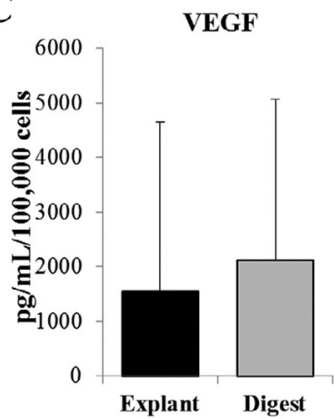

D

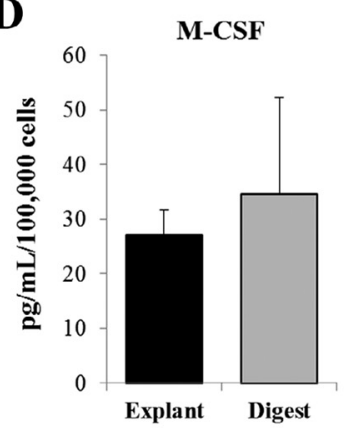

$\mathbf{E}$

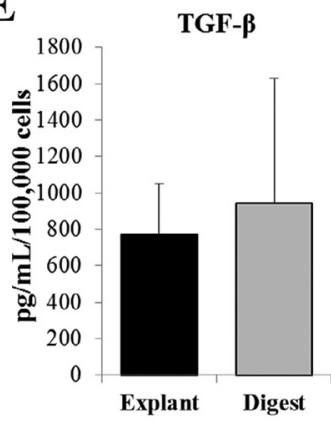

Explant

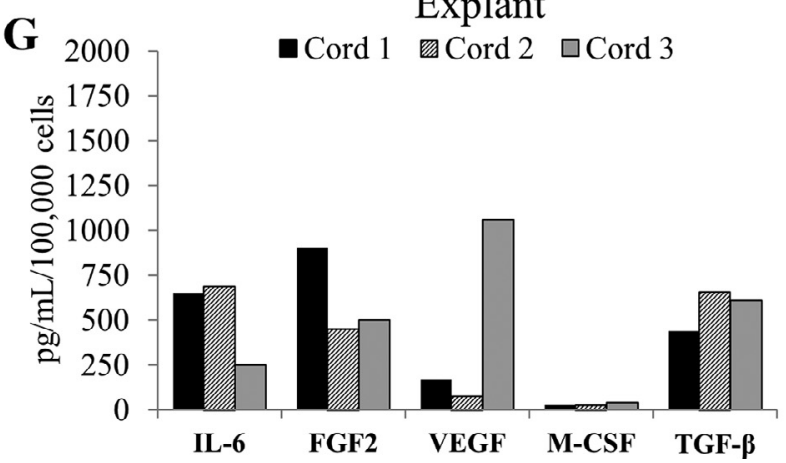

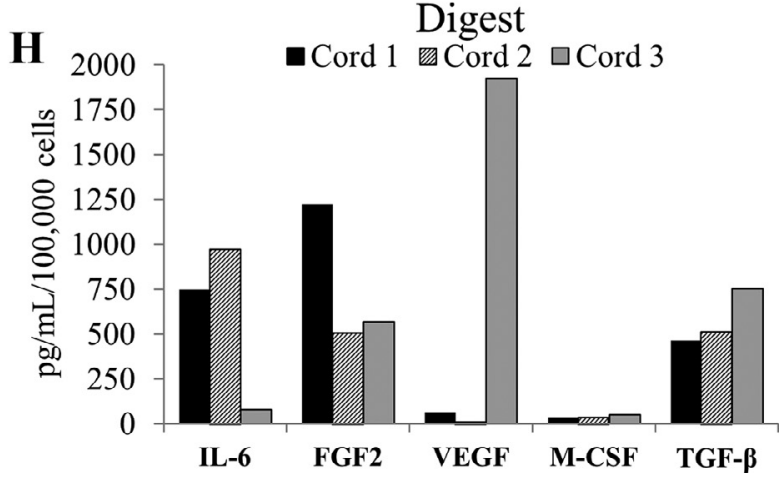

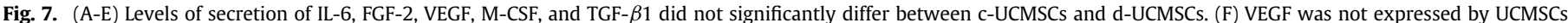

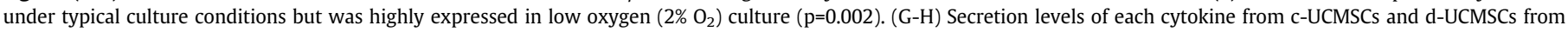
three representative umbilical cord samples demonstrating significant sample-to-sample variation.

employed by cord tissue banks can vary, with differences including removal of blood vessels and/or amnion, enzyme cocktail composition and concentration, digestion duration and mechanical tissue separation steps. We chose to replicate a single industry-validated digestion method and report lower initial cell yields than from explantation of the same tissue; however, it is worth recognizing that cell recovery can be very sensitive to the particulars of the digestion protocol and that a differently optimized procedure may produce different results. Nonetheless, sensitivity of digestion outcomes to the particulars of the procedure may suggest a benefit of the explantation approach. Regardless of differences in cell populations between initial explant and digest harvests, population heterogeneity in cells isolated by digestion was eliminated in subsequent culture passages, with c-UCMSCs and d-UCMSCs being indistinguishable by the end of the first subculture. By contrast, cells harvested at the end of explant culture were uniform in morphology and proliferation, suggesting that only UCMSCs were migrating from the tissue.

Functionally, MSCs are known to secrete a number of soluble growth factors that play a role in local tissue regeneration and suppression of the immune response. The immunomodulatory factors
IL-6, M-CSF and transforming growth factor $\beta 1$ and the pro-angiogenic mitogens fibroblast growth factor 2 and VEGF accumulated in c-UCMSC and d-UCMSC supernatants to similar, physiologically significant levels over $48 \mathrm{~h}$. Production of these cytokines by MSCs has been reported in the literature [29]. Notably, VEGF, M-CSF and transforming growth factor $\beta$, which would be expected to exhibit temporary upregulation in a wound environment, required stimulatory induction by hypoxia (VEGF) or inflammatory factors interferon $\gamma$ and tumor necrosis factor $\alpha$ (M-CSF and transforming growth factor $\beta$ ) to achieve significant secretion. This points to the responsive nature of UCMSCs and supports the suggestion that UCMSCs can be pre-conditioned or "primed" to influence a particular therapeutic property [30]. Additionally, both c-UCMSCs and d-UCMSCs displayed similar capacity to differentiate into osteo-, adipo- and chondrogenic lineages, suggesting that, following enrichment in culture, cells obtained by both isolation methods are functionally equivalent.

Novel as recently as a decade ago, UC tissue banking is now commonplace, led by family newborn stem cell banks recognizing the enormous potential of UCMSCs in regenerative medicine and other 
Alizarin Red S
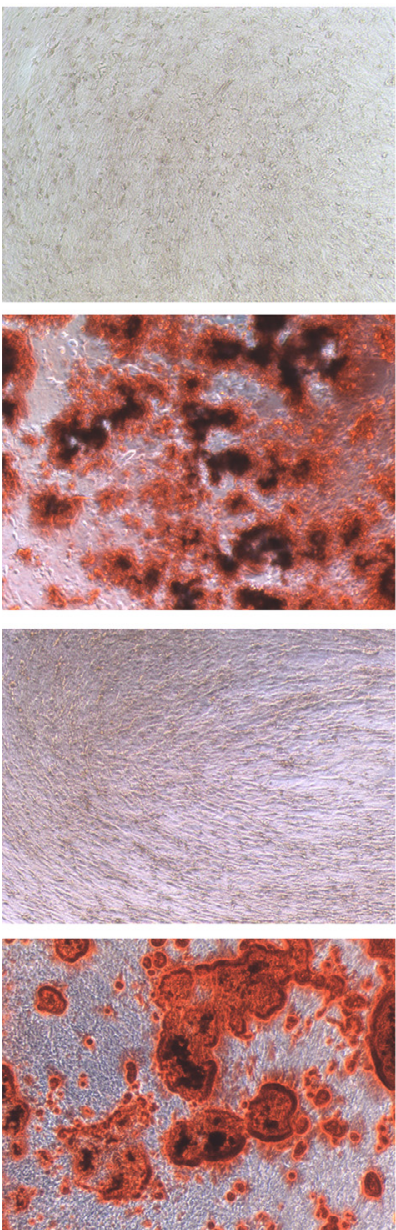

ALP Activity

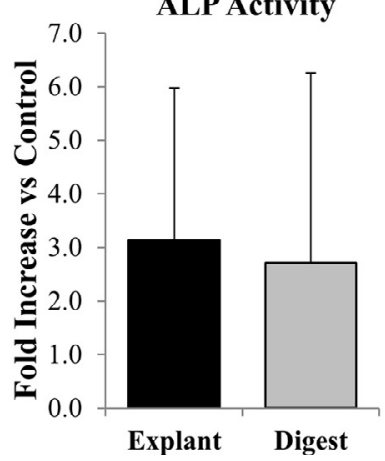

Oil Red O
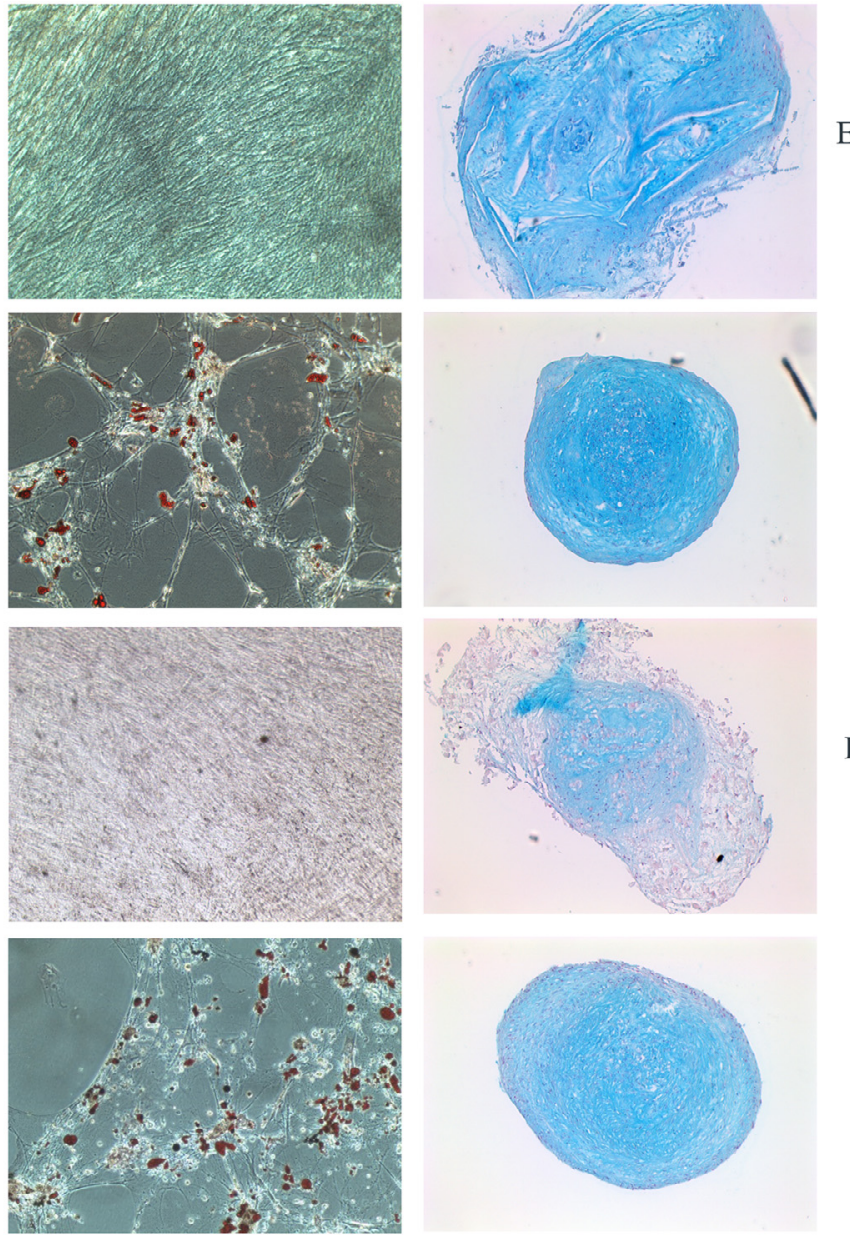
Explant Control,
End of $\mathrm{P} 4$
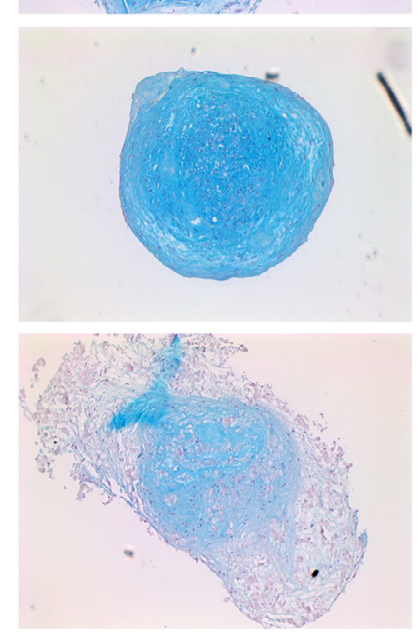

Digest Control, End of P4

Digest Test,
End of P4

Explant Test, End of P4

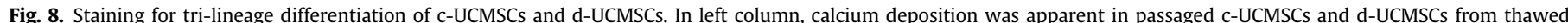

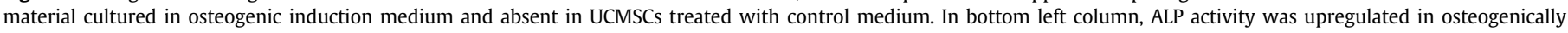

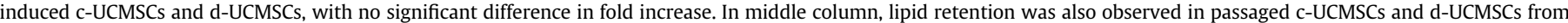

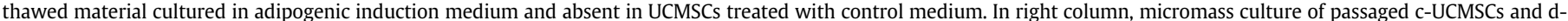

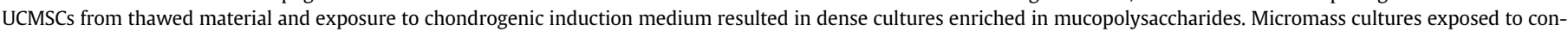

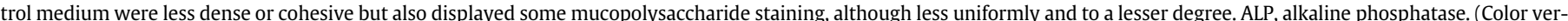
sion of figure is available online).

therapeutic applications. With the number of banked units already in the hundreds of thousands or more, it is important to confirm that (i) cryopreserved UC material reliably retains functional UCMSCs with properties suitable for future clinical use, (ii) the common methods of UC tissue processing and UCMSC isolation do not compromise the identity or functionality of the derived UCMSCs and (iii) UCMSCs can be generated in therapeutically relevant quantities from cryopreserved UC material. We demonstrate that UCMSCs with characteristic MSC qualities can be recovered both from the cryopreserved, heterogeneous cell product of UC tissue digestion and from cryopreserved, composite UC tissue pieces cultured in explant following thaw. Furthermore, once isolated and purified by culture in MSC-selective medium, UCMSCs isolated by either processing method demonstrate indistinguishable MSCs with regard to functional attributes and identity. Finally, we estimate that over three passages following isolation, a $10-\mathrm{g}$ umbilical cord could provide on the order of $10^{12}$ cells from explanted tissue and nearly $10^{11}$ cells from digested tissue (Figure 9). Given that the commonly referenced cell dose for potential MSC therapies is on the order of $10^{6-7}$ cells $/ \mathrm{kg}$, yields by either method fall squarely in the therapeutically relevant range $[10,12,13,15]$. 
A

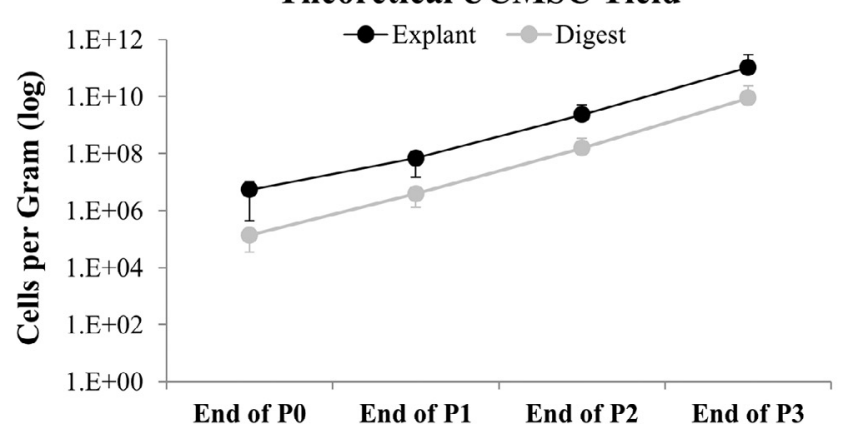

B

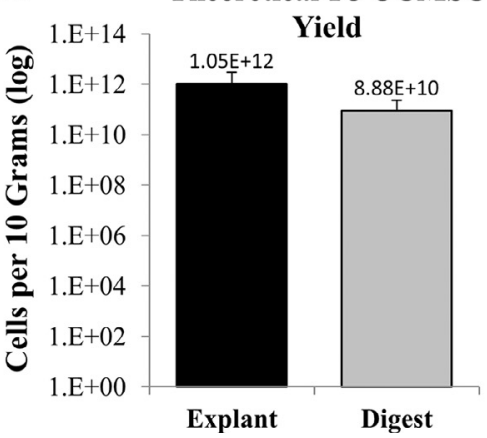

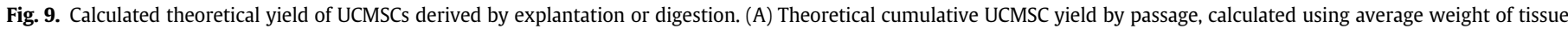

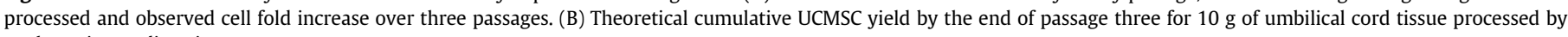
explantation or digestion.

As both cryopreservation of composite UC tissue and storage of a heterogeneous digest are acceptable for maintenance of MSC properties, it is incumbent upon the individual banking institution to identify the most appropriate collection and processing strategy. Isolation of cord tissue MSCs from a previously cryopreserved composite tissue provides for a robust process amenable to the setting of highthroughput newborn stem cell banking [21]. This approach is especially well suited to the setting of private newborn stem cell banking, where there are numerous variables external to the banking operation and every unit is inherently unique. Here we build upon previous findings by reporting that a strategy for large-scale banking of cord tissue utilizing cryopreserved composite material does not compromise the functional attributes of the cells and, furthermore, that the post-thaw yields favor explantation over our digestion approach as an isolation method because of the greater purity of cells and higher per gram yields achieved

\section{Funding}

This work was performed with funding from Cbr Systems, Inc, a Generate Life Sciences company.

\section{Declaration of Competing Interest}

Cbr Systems, Inc (Cord Blood Registry), is an affiliate of Generate Life Sciences. MS, AM, KB and JS receive payment as employees of Generate Life Sciences.

\section{Author Contributions}

Conception and design of the study: Matthew Skiles, Allen Marzan, Katherine Brown, Jaime Shamonki. Acquisition of data: Matthew Skiles, Allen Marzan. Analysis and interpretation of data: Matthew Skiles, Allen Marzan, Katherine Brown. Drafting or revising the manuscript: Matthew Skiles, Allen Marzan, Katherine Brown, Jaime Shamonki. All authors have approved the final article.

\section{Acknowledgments}

The authors thank Evie Hadley for the collection of donated umbilical cord tissue. The authors also thank the University of Arizona Tissue Acquisition and Cellular/Molecular Analysis Shared Resource facility for histological preparation of micromass cultures.

\section{References}

[1] Dominici M, Le Blanc K, Mueller I, et al. Minimal criteria for defining multipotent mesenchymal stromal cells. Cytotherapy 2006;4:315-7.
[2] Ullah M, Liu DD, Thakor AS. Mesenchymal stromal cell homing: mechanisms and strategies for improvement. iScience 2019;15:421-38

[3] Young HE. Existence of reserve quiescent stem cells in adults, from amphibians to humans. Curr Top Microbiol Immunol 2004;280:71-109.

[4] Cook D, Genever P. Regulation of mesenchymal stem cell differentiation. Adv Exp Med Biol 2013;786:213-29.

[5] Fu Y, Karbaat L, Wu L, Leijten J, Both SK, Karperien M. Trophic effects of mesenchymal stem cells in tissue regeneration. Tissue Eng Part B Rev 2017;23(6):515-28.

[6] Weiss ARR, Dahlke MH. Immunomodulation by mesenchymal stem cells (MSCs): mechanisms of action of living, apoptotic, and dead MSCs. Front Immunol 2019;10:1191.

[7] Sahai S, Wilkerson M, Xue H, Moreno NF, Carrillo LA, Flores R, Greives MR, Olson $\mathrm{SD}, \mathrm{Cox} \mathrm{CS}$, Triolo F. Wharton's jelly for augmented cleft palate repair in a rat critical size alveolar bone defect. Tissue Eng Part A 2020;26(11-12):591-601.

[8] Mu D, Zhang XL, Xie J, Yuan HH, Huang W, Li GN, Lu JR, Mao LJ, Wang L, Cheng L, Mai XL, Yang J, Tian CS, Kang LN, Gu R, Zhu B, Xu B. Intracoronary transplantation of mesenchymal stem cells with overexpressed integrin-linked kinase improves cardiac function in porcine myocardial infarction. Sci Rep 2016;6:19155.

[9] van Velthoven CT, Sheldon RA, Kavelaars A, Derugin N, Vexler ZS, Willemen HL, Maas M, Heijnen CJ, Ferriero DM. Mesenchymal stem cell transplantation attenuates brain injury after neonatal stroke. Stroke 2013;44(5):1426-32.

[10] Kota DJ, Prabhakara KS, van Brummen AJ, Bedi S, Xue H, DiCarlo B, Cox Jr CS, Olson SD. Propranolol and mesenchymal stromal cells combine to treat traumatic brain injury. Stem Cells Transl Med 2016;5(1):33-44.

[11] ClinicalTrials.gov. MD, USA: National Library of Medicine (USA). 2018 March 22-. Identifier NCT03473301, A study of UCB and MSCs in children with CP:ACCeNTCP (ACCeNT-CP). https://clinicaltrials.gov/ct2/show/NCT03473301.

[12] Tanaka E, Ogowa Y, Mukai T, Sato Y, Hamazaki T, Nagamura-Inoue T, HaradaShiba M, Shintaku H, Tsuji M. Dose-dependent effect of intravenous administration of human umbilical cord-derived mesenchymal stem cells in neonatal stroke mice. Front Neurol 2018;9:133.

[13] Chang YS, Ahn SY, Yoo HS, Sung SI, Choi SJ, Oh WI, Park WS. Mesenchymal stem cells for bronchopulmonary dysplasia: phase 1 dose-escalation clinical trial. J Pediatr 2014;164(5):966-72.

[14] Wang D, Zhang H, Liang J, Wang H, Hua B, Feng X, Gilkeson GS, Farge D, Songtao Shi, Sun L. A long-term follow-up study of allogeneic mesenchymal stem/stromal cell transplantation in patients with drug-resistant systemic lupus erythematosus. Stem Cell Reports 2018;10(3):933-41.

[15] Kurtzberg J, Prockop S, Teira P, Bittencourt H, Lewis V, Chan KW, Horn B, Yu L, Talano JA, Nemecek E, Mills CR, Chaudhury S. Allogenic human mesenchymal stem cell therapy (remestemcell-L, Prochymal) as a rescue agent for severe refractory graft-versus-host disease in pediatric patients. Biol Blood Marrow Transplant 2014;20(2):229-35.

[16] Hass R, Kasper C, Böhm S, Jacobs R. Different populations and sources of human mesenchymal stem cells (MSC): a comparison of adult and neonatal tissuederived MSC. Cell Commun Signal 2011;9:12.

[17] Li Z, Han ZC. Introduction of perinatal tissue-derived stem cells. Perinatal Stem Cells 2019: 1-8.

[18] Davies JE, Walker JT, Keating A. Concise review: Wharton's jelly: the rich, but enigmatic, source of mesenchymal stromal cells. Stem Cells Transl Med 2017;6 (7):1620-30.

[19] Couto PS, Shatirishvili G, Bersenev A, Verter F. First decade of clinical trials and published studies with mesenchymal stromal cells from umbilical cord tissue. Regen Med 2019;14(4):309-19.

[20] Brown KS, Rao MS, Brown HL. The future state of newborn stem cell banking. J Clin Med 2019;8(1):117.

[21] Skiles ML, Brown KS, Tatz W, Swingle K, Brown HL. Quantitative analysis of composite umbilical cord tissue health using a standardized explant approach and an assay of metabolic activity. Cytotherapy 2018;20(4):564-75.

[22] Mushahary D, Spittler A, Kasper C, Weber V, Charwat V. Isolation, cultivation, and characterization of human mesenchymal stem cells. Cytometry A 2018;93(1): 19-31. 
[23] Spurway J, Logan P, Pak S. The development, structure and blood flow within the umbilical cord with particular reference to the venous system. Australas J Ultrasound Med 2012;15(3):97-102.

[24] Sarugaser R, Lickorish D, Baksh D, Hosseine MM, Davies JE. Human umbilical cord perivascular (HUCPV) cells: a source of mesenchymal progenitors. Stem Cells 2005;23(2):220-9.

[25] Lu LL, Liu YJ, Yang SG, Zhao QJ, Wang X, Gong W, Han ZB, Xu ZS, Lu YX, Liu D, Chen ZZ, Han ZC. Isolation and characterization of human umbilical cord mesenchymal stem cells with hematopoiesis-supportive function and other potentials. Haematologica 2006;91(8):1017-26.

[26] Iftimia-Mander A, Hourd P, Dainty R, Thomas RJ. Mesenchymal stem cell isolation from human umbilical cord tissue: understanding and minimizing variability in cell yield for process optimization. Biopresrev Biobank 2013;11(5):291-8.
[27] Salehinejad P, Alitheen NB, Ali AM, Omar AR, Mohit M, Janzmine E, Samani FS, Torshizi Z, Nematollahi-Mahini SN. Comparison of different methods for the isolation of mesenchymal stem cells from human umbilical cord Wharton's jelly. In Vitro Cell Dev Biol Anim 2012;48(2):75-83.

[28] Yoon JH, Roh EY, Shin S, Jung NH, Song EY, Chang JY, Kim BJ, Jeon HW. Comparison of explant-derived and enzymatic digestion-derived MSCs and the growth factors from Wharton's jelly. Biomed Res Int 2013;2013:428726.

[29] Vizoso FJ, Eiro N, Cid S, Schneider J, Perez-Fernandez R. Mesenchymal stem cell secretome: toward cell-free therapeutic strategies in regenerative medicine. Int J Mol Sci 2017;18(9):1852.

[30] Ferreira JR, Tiexeira GQ Santos SG, Barbosa MA, Almeida-Porada G, Gonçalves RM. Mesenchymal stromal cell secretome: influencing therapeutic potential by cellular pre-conditioning. Front Immunol 2018;9:2837. 